\title{
Amputação interescapulotorácica sob anestesia locorregional
}

\section{Forequarter amputation under locoregional anesthesia}

\author{
José Alves de Moraes'; Tarcisio José Cysneiros da Costa Reis, tCBC/PE2; Holmes Naspolini Filho3; Thales Paulo Batista, TCBC/ \\ PÉ, Márcia Angélia de LuCEnA 5
}

\section{INTRODUÇÃO}

\begin{abstract}
A abordagem multidisciplinar dos sarcomas tem propiciado crescente redução da necessidade de grandes amputações durante seu manejo cirúrgico, no entanto, a amputação interescapulotorácica se mantém como alternativa terapêutica aos procedimentos conservadores naqueles tumores localmente avançados envolvendo a axila e o ombro.

Dado se tratar de operação de maior porte cirúrgico, esse tipo de procedimento geralmente é efetuado sob anestesia geral. Contudo, relata-se neste artigo, a realização de amputação interescapulotorácica para o tratamento de sarcoma de partes moles envolvendo a axila e ombro, executada sob anestesia locorregional e sedação venosa.
\end{abstract}

\section{RELATO DO CASO}

Paciente do sexo feminino, 64 anos, parda, apresentou-se para reavaliação ambulatorial com tumoração extensa e ulcerada na face interna do braço direito estendendo-se até a região axilar, associada à parestesia e impotência deste membro, porém sem ocorrência de dor espontânea.

Tratava-se de paciente anteriormente submetida à múltiplas ressecções para o tratamento de fibrohistiocitoma maligno recidivante, que negara, há oito meses, submeter-se à desarticulação do ombro, devido à constatação radiológica de envolvimento tumoral da articulação do ombro e do plexo neuro-vascular da axila (Estádio Clínico III - T2bNOMOG4).

A paciente apresentava importantes doença cardiovascular confirmada pelo estudo hemodinâmico cardíaco: dominância da artéria coronária direita com obstrução de $20 \%$ em seu tronco e de $50 \%$ em seu ramo descendente posterior; artéria coronária esquerda com obstrução de $45 \%$ de seu terço inferior, obstrução ostial grave de seu ramo diagonal, acompanhada de $85 \%$ de obstrução de seu ramo circunflexo; além de hipertrofia ventricular esquerda com função global e segmentar preservadas.

Tendo em vista o atraso do tratamento devido à recusa inicial da paciente, o risco anestésico-cirúrgico inerente ao tratamento proposto, optou-se pela realização da cirurgia sob técnica anestésica locorregional, com o objetivo diminuir seu porte anestésico e minimizar os riscos de complicações cardiovasculares.

Assim, procedeu-se ao bloqueio do plexo braquial por via interescalena anterior (Figura 1) associando à sedação com fentanila e midazolam em doses usuais. O bloqueio foi complementado por infiltração do sítio cirúrgico torácico com solução racêmica de lindocaína $1 \%$ e bupivacaína $0,125 \%(40 \mathrm{ml})$, utilizada durante a confecção do retalho cutâneo posterior para debelar os poucos e fugazes reflexos dolorosos observados no início deste tempo cirúrgico.

A operação transcorreu sem maiores dificuldades e o fechamento da área cruenta foi realizado, primariamente, pela confecção de retalhos cutâneos e utilização de drenagem subcutânea à vácuo. A paciente foi en-

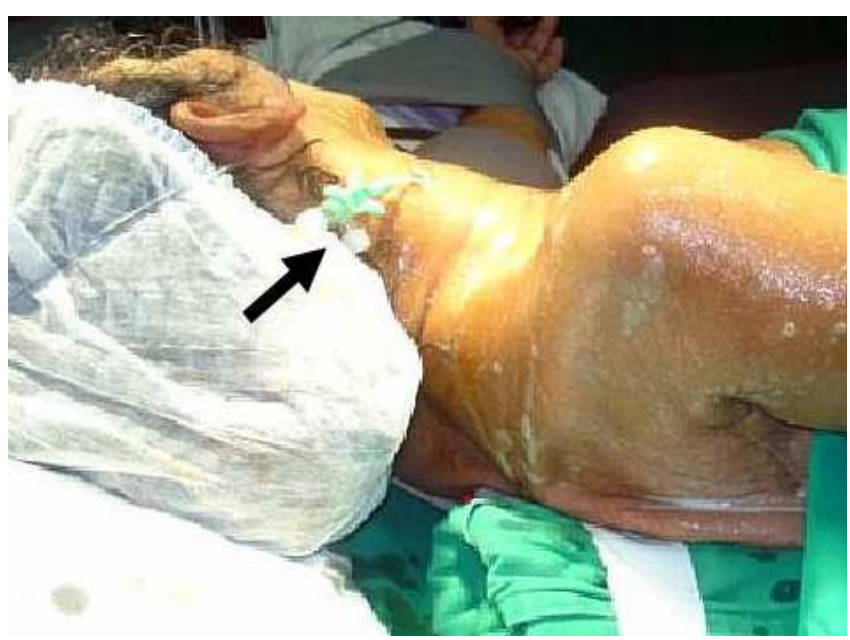

Figura 1 - Cateter cervical (seta) inserido para bloqueio do plexo braquial por via interescalena anterior.

Trabalho realizado no Centro de Oncologia do Hospital Universitário Oswaldo Cruz/Universidade de Pernambuco - CEON/HUOC/UPE, Recife - PE. 1. Cirurgião Oncologista do Centro de Oncologia do Hospital Universitário Oswaldo Cruz/Universidade de Pernambuco - CEON/HUOC/UPE; 2. Coordenador da Residência Médica em Cirurgia Oncológica do HUOC/UPE; 3. Anestesiologista do HUOC/UPE; 4. Cirurgião Oncologista do Serviço de Cirurgia Geral da Faculdade Pernambucana de Saúde e Instituto de Medicina Integral Professor Fernando Figueira - FPS/IMIP; 5. Cirurgiã Oncologista do Departamento de Pelve do Hospital de Câncer de Pernambuco - HCP. 
caminhada à enfermaria após a alta anestésica e evoluiu sem intercorrências até receber alta hospitalar no quinto dia de pós-operatório, com orientações sobre o seu egresso ambulatorial.

O exame anátomo-patológico da peça cirúrgica (Figura 2) confirmou o estádio clínico inicial, e a paciente foi encaminhada para radioterapia adjuvante, encontrando-se sem evidências de recidiva após 40 meses de proservação.

\section{DISCUSSÃO}

Inicialmente proposta em meados do século XIX para o tratamento de lesões traumáticas envolvendo a cintura escapular, a amputação interescapulotorácica, também tem sido empregada para o controle local de vários tipos de tumores malignos envolvendo a região da axila e ombro, onde uma operação conservadora não pôde ser indicada, devido à extensão ou características do tumor ${ }^{1-4}$.

Tecnicamente, a amputação do ombro pode ser realizada por via anterior (Berger), posterior (Littlewood) ou por uma combinação delas ${ }^{2,4}$. Em nosso Serviço, a abordagem anterior tem sido preferida, por ser aquela com a qual os autores estão mais familiarizados e por proporcionar, pelo menos empiricamente, uma desejável sensação de segurança pela abordagem precoce do plexo vascular.

O bloqueio do plexo braquial pode ser realizado em cinco diferentes níveis: interescaleno, supraclavicular, infraclavicular, axilar e umeral médio. A abordagem interescalena é a mais cranial delas e pode ser realizada por via posterior ou anterior. Este nível de bloqueio anestésico costuma ser empregado para procedimentos sobre o ombro, clavícula lateral e úmero proximal e e apresenta como potenciais efeitos colaterais a paralisia frênica ipsilateral e do nervo recorrente laríngeo, síndrome de Horner, punções vasculares iatrogênicas e pneumotórax. Suas contra-indicações estão relacionadas ao sítio de punção, como infecções tegumentares locais, ou à presença

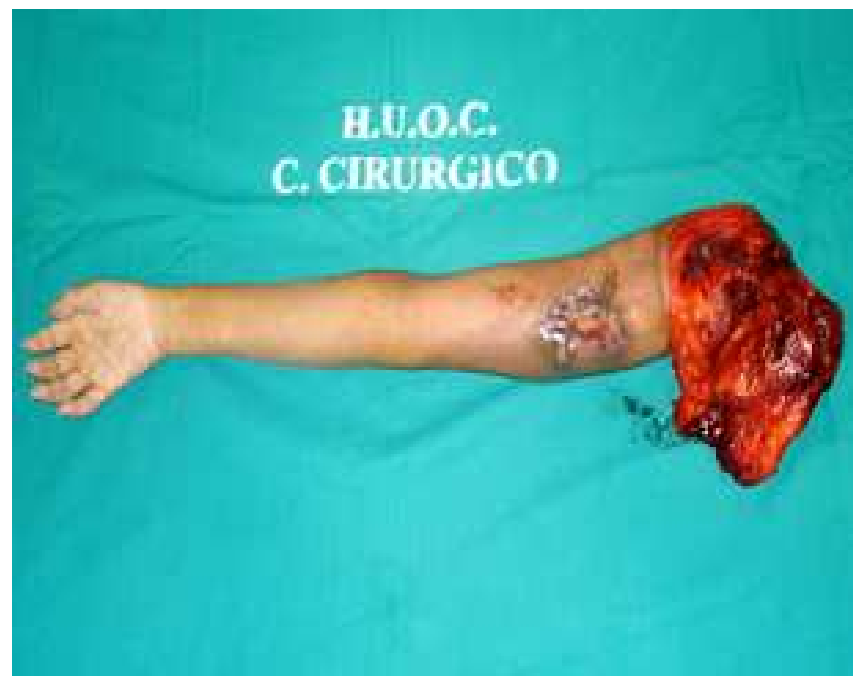

Figura 2 - Peça cirúrgica da amputação interescapulotorácica.

de paralisia frênica e do nervo recorrente laríngeo. Apresenta, portanto, limitação em casos de comorbidades respiratória, principalmente insuficiência respiratória e DPOC, mas causa pouca repercussão sobre o sistema cardiovascular, exceto pelo potencial efeito cardiotóxico dose-dependente dos anestésicos locais empregados. No caso apresentado, este último inconveniente pôde ser facilmente minimizado pelo uso cuidadoso de técnica anestésica combinada, tornando o método aplicável e adequado para o contexto clínico descrito.

O referido caso chama atenção pela ausência de dor à apresentação, apesar da extensão tumoral, assim como, pelo emprego de técnica cirúrgica radical menos comum comum para os dias de hoje e pela abordagem anestésica utilizada. Nele, o bloqueio do plexo braquial por via interescalena complementado por sedação venosa e infiltração das linhas de incisão torácicas com anestésicos locais permitiu a desarticulação do ombro com adequada segurança para a paciente e conforto para a equipe cirúrgica.

\section{A B S T R A C T}

Forequarter amputations are an uncommon option for the treatment of upper limb and shoulder girdle tumors nowadays. This procedure can be done by different approaches and general anesthesia is commonly used. The authors report a case of forequarter amputation by the posterior approach performed for treatment of a soft-tissue sarcoma under a brachial plexus block associated with venous sedation and local anesthesia.

Key words: Amputation. Brachial plexus. Anesthesia. Neoplasms. Sarcoma.

\section{REFERENNCIAS}

1. Levine EA, Warso MA, McCoy DM, Das Gupta TK. Forequarter amputation for soft tissue tumors. Am Surg. 1994;60(5): 367-70.
2. Ferrario T, Palmer P, Karakousis CP. Technique of forequarter (interscapulothoracic) amputation. Clin Orthop Relat Res. 2004;(423):191-5.

3. Clark MA, Thomas JM. Major amputation for soft-tissue sarcoma. Br J Surg. 2003;90(1):102-7. 
4. Sugarbaker PH. Forequarter amputation. In: Sugarbaker PH Malawer MM, editors. Musculoskeletal surgery for cancer: principles and techniques. New York: Thieme Medical; 1992. p.30616.

Recebido em 05/07/2007

Aceito para publicação em 15/08/2007

Conflito de interesse: nenhum

Fonte de financiamento: nenhuma

\section{Como citar este artigo:}

Moraes JA, Reis TJCC, Naspolini Filho H, Batista TP, Lucena MA. Amputação interescapulotorácica sob anestesia locorregional. Rev Col Bras Cir. [periódico na Internet] 2013;40(5). Disponível em URL: http:// www.scielo.br/rcbc

Endereço para correspondência:

Tarcisio José Cysneiros da Costa Reis

E-mail: tcr@hotlink.com.br 